\title{
Bullying, overweight and physical activity in school children of Karachi

Musleh uddin Kalar ${ }^{1}$, Tashaba Qaiser Faizi², Maheen Jawed ${ }^{2}$, Sumaira Khalit², Sara M Hussain2, Mushkbar Fatima ${ }^{2}$, Faiza Aslam², Hasnain Abbas Dharamshi², Tahira Naqvi ${ }^{2}$

\section{Abstract}

The pessimistic community and emotional consequence of childhood obesity together with being liked to a less significant extent by peers, being rejected by peers, and being the victims of various structure of peer violence such as bullying are a major teenage dilemma. Bullying comprises of a variety of actions that result in a disparity of supremacy involving the assailant and the sufferer. Bullying was evaluated by Olweus Bullying Questionnaire (OBQ) and BMI was estimated by Childhood Obesity Working Group of the International Obesity Task Force. In response to the question how often you bullied at school in past couple of months $38.81 \%$ students replied once or twice, 9\% students replied several times a week, 6.2\% students replied once a week. BMI categories (Normal Weight/Overweight and Obese) was compared with the Olweus Bullying Questionnaire, I as hit, kicked, punched, thrown around the door on chi square test which showed statistically significant results $(p=0.036)$. Bullying was significantly associated with obese school children. There should be proper knowledge and understanding of students regarding what bully actually is and report to their teachers and parents.

1 University of Saskatchewan, Canada

2 Karachi Medical and Dental College, Karachi, Pakistan

Contact information:

\section{Hasnain Abbas Dharamshi}

”d dr.hasnain.dh@hotmail.com

Keywords

Bullying; Overweight; Physical activity. 


\section{Introduction}

Childhood obesity is one of the most serious public health challenges of the $21^{\text {st }}$ century. The problem is global and is steadily affecting many lowand middle-income countries, particularly in urban settings. The prevalence has increased at an alarming rate. Globally, in 2010 the number of overweight children under the age of five is estimated to be over 42 million. Close to 35 million of these were living in developing countries. Overweight and obese children are likely to stay obese into adulthood and more likely to develop non-communicable diseases like diabetes and cardiovascular diseases at a younger age [1]. The prevalence of overweight in children has increased in almost all countries. Obesity and overweight have increased worldwide and even more dramatically in economically developed countries and in urbanized populations [2].

The negative social and psychological ramifications of childhood obesity including being liked to a lesser extent by peers, being rejected by peers, and being the victims of various forms of peer aggression such as bullying are also of prime significance [3-8]. Bullying includes a range of behaviors that result in an imbalance of power between the aggressor and the victim [9]. Such behaviors include not only physical aggression but also verbal harassment and public humiliation (example: namecalling and spreading rumors). Indeed, emotional bullying by peers is especially a concern for youth, [10] and recent school shootings suggest that it is not physical abuse by peers but inability to cope with social ridicule and personal rejection that can fuel extreme outbursts of violence [11]. Bullying behaviors may be related to body size and obesity in adolescence [12]. The statistics on bullying are upsetting. In a recent national survey of overweight sixth graders, $24 \%$ of boys and $30 \%$ of girls experienced daily teasing, bullying or rejection because of their size. The number doubles for overweight high school students with $58 \%$ of boys and $63 \%$ of girls experiencing daily teasing and bullying [13]. Students involved in bullying are at a significant risk of experiencing a wide spectrum of psychosomatic symptoms, running away from home, alcohol and drug abuse, absenteeism and above all self-inflicted, accidental or perpetrated injuries [14]. There is a positive association between overweight, obesity, aggression and victimization in youth [15-20]. Studies have emphasized the forms of aggression that are salient to boys (example: teasing or physical bullying), whereas the forms of aggression that are salient to girls (example: relational) have largely been ignored [21].

The purpose of study is to determine physical activity, non physical activities (watching TV or video gaming), sleeping hours, eating habit and frequency of breakfast effect school going children. This study will also assess the association of BMI with bullying victims, and the frequency of perpetrators in girls, boys, peers or seniors of bully and victim. The objective of this study was to determine the frequency of bullying, overweight and physical activity in school children of Karachi.

\section{Materials and methods}

\section{Study design and study cases}

A questionnaire based comparative cross sectional study was conducted in a private school of Karachi, Pakistan from February 2014 till July 2014. In regards to overweight and physical activity few questions were designed by qualified nutritionist. The questionnaire included data on the demographic profile of the subject age, gender, participation in sports, sleeping habit in afternoon, restaurant visit per week, junk food intake, family history of diabetes and family history of obesity. Questionnaire was administered in both "English" and "Urdu" languages, depending on child comfort ability. Urdu is the national language of Pakistan. The participants of this study were school children of, $13-18$ 
years of age which were selected on the basis of non probability convenient sampling. Bullying was assessed by Olweus Bullying Questionnaire (OBQ) which is a standardized, validated, multiple-choice questionnaire designed to measure a number of aspects of bullying problems in schools. The OBQ, is typically used with students in grades 3 through 12. The students filled out the questionnaire anonymously.

\section{Psychometric Properties of Olweus Bullying Questionnaire}

With individual subjects as the unit of analysis, sums or means of group of questions about being bullied (Questions 5-13), respectively, have typically yielded internal consistency reliabilities (Cronbach's alpha) of 0.80 or higher. The results for younger students in grades 4 or 5 have been about as good as for students in the middle school/junior high school grades. In assessing the prevalence of bullying problems (using Question 4) in larger units, such as in schools or in school districts, the reliabilities have been even higher, typically in the 0.85-0.95 range. Both individuals and schools/districts can thus be very well differentiated with the OBQ. Strong evidence has also been documented for the usefulness and (construct) validity of the questionnaire variable of "being bullied" (Question 4) by examining the association between degree or frequency of victimization and relevant other variables. In these analyses, strong (linear) associations between degree/frequency of being bullied and variables such as depressive mood, poor self-esteem, and peer rejection have been found. For example, the more often a student has been exposed to bullying in the past couple of months, the higher his or her level of depressive mood (on average). Furthermore, clear evidence of another form of validity-criterionrelated validity-with sums of 3-5 self-report items (identical or similar to those in the $\mathrm{OBQ}$ ) on being bullied or bullying other students correlating in the 0.40 to 0.60 range with reliable peer ratings on related dimensions have been found. These validity correlations are approximately the same as those of the best personality questionnaires. Also, other forms of peer ratings have been shown to correlate substantially with estimates of being bullied/ bullying other students based on the students' own reports. The reported results indicate that there is a good deal of overlap between self-report estimates of bullying problems and estimates derived from independent peer ratings intended to measure the same or similar phenomena. Given the nature of bullying, it is reasonable to assert that a wellconstructed questionnaire such as the OBQ is likely to provide reliable, largely valid, and relevant data on the phenomena of interest $[22,23,24,25]$.

\section{Body Mass Index Measurement and Obesity Classification \\ Assessment of BMI:}

Body Mass Index (BMI) was calculated by Centers for Disease Control and Prevention (CDC). This calculator provides BMI for-age. This calculator can be used till 19 years aged teenagers. ${ }^{26}$

\section{Children's BMI Tool for Schools:}

The Children's BMI Tool for Schools is an Excel spreadsheet to compute Body Mass Index (BMI)for-age. This calculator computes BMI for individual children in a group using height and weight measurements, sex, date of birth, and date of measurement information that has been entered, or imported from a spreadsheet or data file. It provides a group summary of children's BMI-for-age categories and graphs for Prevalence of Overweight and Obesity, and Prevalence of Overweight and Obesity by Sex. Body Mass Index (BMI) is a number calculated from a child's weight and height. BMI is a reliable indicator of body fatness for children and teens. For children and teens, BMI is age- and sex-specific and is often referred to as BMI-for-age. ${ }^{26}$

The sample size calculation was done by using the World Health Organization (W.H.O.) software 
for "Sample Size Calculation" edited by L. Lemeshow and S. K. Lwanga. The results of this study are valid as confirmed by sample size calculation, where $\alpha=5 \%, 1-\beta=90, P_{1}=0.05, P_{2}=0.10, n$ (sample size) $=221$. The researcher recruited 420 subjects to avoid the chances of type 2 error.

Children included in the study had vaccination status according to the Expanded Program of Immunization of Pakistan and had no history of chronic illnesses. Children having repeated hospitalization were excluded. Questionnaire was administered and school children were asked to provide answers based on the frequency of bullying and victimization. Questions were also asked whether they participate in sports; afternoon sleep; restaurant visit per week; intake of junk food; family history of diabetes and family history of obesity. The data were collected on the questionnaire without the names of the participants so that anonymity could be maintained.

\section{Statistical Analysis}

Data was entered on Statistical Package for Social Sciences (SPSS) Version 20 and analyzed. A descriptive analysis was performed; continuous variables (age, number of hours watching TV/playing video games per day, number of times a sport is played per week (defined as $>45$ minutes of activity ${ }^{17}$ ) were presented as mean \pm standard deviation (SD). Categorical variables (gender, participation in sports, daily exercise, sleep in afternoon, restaurant visit per week, intake of junk food, eating chocolate, family history of diabetes, family history of obesity and Questions from Olweus Bullying Questionnaire were presented as proportions (\%).

The characteristics of obese school children were compared with non-obese school children. The study population was categorized into obese and non obese groups. Binary logistic regression analysis was performed to assess the predictors for the dependent variable of obesity, with a threshold for the selection of $p<0.05$. Independent variables were participation in sports, sleeping habit in afternoon, restaurant visit per week, takes junk food regularly, family history of diabetes, family history of obesity. Questions from Olweus Bullying Questionnaire were also compared with BMI for statistical significance.

\section{Results}

The mean age of non obese school children was 14 years \pm 1.21 and of obese were 15 years \pm 1.55 . Non obese male school children were $78.8 \%$ and obese male school children were $21.2 \%$. Non obese female school children were $66.7 \%$ and obese female school children were $33.3 \%$. Mean number of times a sport is played per week (defined as $>45$ minutes of activity) was $2.41 \pm 1.09$ hours in non obese and $2.62 \pm 0.48$. Mean BMl in non obese school children was $23.76 \pm 0.43$ and in obese school children was $30.38 \pm 0.78$. In response to the question good friend in the class $37.1 \%$ students replied 6 or more friends, $22.1 \%$ students replied 4 or more friends, $11.2 \%$ students replied 1 friend, and $0.2 \%$ students replied 6 friends.

In response to the question how often you bullied at school in past couple of months 38.81\% students replied once or twice, 9\% students replied several times a week, 6.2\% students replied once a week. In response to the question, have they ever been left by other students, excluded from students group, or got ignored, $20 \%$ students replied once or twice, $4.8 \%$ replied 2 or 3 times a month $2.6 \%$ replied several times a week, $1.7 \%$ replied once a week. A lot of students about 20.48\% answered that they were hit, kick and pushed, thrust around locked in doors once or twice, $4.8 \%$ said several times a week, $4.3 \%$ said 2 or 3 times a month, $2.1 \%$ students said once a week. In the question regarding how many times other students have told lie, spread false rumor about them, and tried others to dislike them, 32.1\% students replied once or twice, $9.3 \%$ replied 2 or 3 times a month, 3.3\% replied several times a week, 3.1\% replied once a 
week. About $19 \%$ of students responded that their money was taken away by senior students once or twice, $4.5 \%$ replied 2 or 3 times in a month, $4 \%$ replied several times a week, 1.9\% replied once a week. About 26\% students answered that they were threatened to do things that they didn't want to do once or twice, $10.7 \%$ replied 2 or 3 times a month, 4.8\% replied once a week, 4.3\% replied several times a week. $26.19 \%$ students replied that they were called by mean names, made fun or teased in hurtful way 2 or 3 times a month,11\% replied several times a week, $8.6 \%$ replied 2 or 3 times a month, $4.3 \%$ replied once a week. A lot of students $31.9 \%$ replied that they were bullied by their class fellow, $6.9 \%$ replied by the students of different grades, $6.2 \%$ students replied by the students of lower grade, $4.8 \%$ replied by high grade students. $15.23 \%$ students replied that they were bullied by 1 boy, 15\% students replied that they were bullied by $1 \mathrm{girl}, 11.9 \%$ students replied they were bullied by several boys, 3.8\% replied they were bullied by several girls. A lot of students $26.4 \%$ replied they were bullied by 1 student, $15.7 \%$ students replied group of 2 or 3 students, $5 \%$ students replied group of more than 9 students. A few students 36.19\% students replied they were bullied in one or more places such as class, school and recess time.

Concerning to the question "have you told anyone that you have bullied in past couple of months" students that shared their experience with someone regarding bullying were $26.7 \%$ and those who didn't discuss with anyone were $22.9 \%$. Students that were bullied told their best friend were $24.5 \%$, those who told their parents were $12.4 \%, 5.5 \%$ told their siblings, while $2.9 \%$ told somebody else. In response to the question that what they feel when they see students of their age being bullied at school, $36.42 \%$ felt sorry for them and wanted to help him/her, $25.5 \%$ replied they didn't feel much, $23.6 \%$ students felt a bit sorry for him/her,14.5\% replied that what he/she probably deserve. A few students $24.52 \%$ students replied that they bullied other students by calling mean names, 5.5\% bullied other by kicking and shoving, 3.8\% had thrown someone out of the group without any problem, while 3.1\% students spread rumors about other students. When students were asked which thing best describe them $56.9 \%$ students replied cool \& popular, $39.8 \%$ replied average, $1.9 \%$ less than other, $1.4 \%$ replied below average.

Concerning the question "what do you do when you feel said $68.1 \%$ replied they stay quiet while $31.9 \%$ replied they talk to teachers or friends. Regarding educational accomplishment $43.1 \%$ students replied that they are excellent in academic activities and achievements,35.5\% replied they are good in one of them,19.8\% replied that are average in all of them, $1.7 \%$ replied they are poor in all. A lot of students $32.4 \%$ students replied they felt lonely in the school, while $67.6 \%$ replied didn't.

BMI categories (Normal Weight/Overweight and Obese) was compared with the Olweus Bullying Questionnaire, I as hit, kicked, punched, thrown around the door on chi square test which showed statistically significant results $(p=0.036)$ see Table 1 .

BMI categories (Normal Weight/Overweight and Obese) was compared with the question I was threatened or forced to do things I didn't want to do on chi square test which showed statistically non significant results $(p=0.500)$ see Table 2 .

Few dietary and physical activity questions were also asked from students among which 19\% students replied that their parents were diabetic and $15.5 \%$ students were having obese parents. A lot of students $60.5 \%$ students replied that they took breakfast more than 5 days a week, while 39.5\% took breakfast less than 5 days a week. About $55.7 \%$ students replied that they eat fast food, light and healthy food and drink soft drinks, 22.9\% replied they eat light and healthy food, while 21.2\% students replied soft drink and fast food. A lot of students $78.8 \%$ replied that they take meal 2 or 3 times a month, $14.3 \%$ replied 3 to 4 times, $6.9 \%$ replied 4 to 5 times. Upon questioning "how many 
number of hours you watch television daily" $61.4 \%$ students replied 2 hours, $17.4 \%$ students replied 3 hours, 9\% replied 4 hours, 3.1\% replied 6 hours, while $2.6 \%$ replied 5 hours. In response to the question "how many number of hours you play video game daily" 59.8\% replied 2 hours, 10\% replied 3 hours, 5\% replied 4 hours, 2.6\% replied 6 hours, $1.7 \%$ replied 5 hours.

In response to the question regarding "taking active participation in sports" $85.7 \%$ students replied yes. In regards to the question "number of times a student play sport per week for more than 45 minutes" 44\% students replied once a week, $22.9 \%$ replied twice a week, $15.5 \%$ replied thrice a week, $7.6 \%$ replied seven times a week, 5\% replied 4 times a week, $4 \%$ replied 6 times a week, $5 \%$ replied 4 times a week, 3.1\% replied 5 times a week. About sleeping in afternoon 54.3\% students replied that they sleep in afternoon while $45.7 \%$ did not .About $49.8 \%$ students replied they visit restaurants per week while $50.2 \%$ said no. Concerning the question "do you eat burger, french fries, snacks or pizza" $89.8 \%$ students replied yes while $10.2 \%$ replied no.

\section{Binary Logistic Regression Analysis}

School children visiting restaurant per week had a high prevalence of obesity as compared to children who do not visit restaurant per week respectively (150/420; 35\% v 25/90; 279\%, $p$-value $=0.045$ ). School children visiting restaurant per week had 1.91 times more, $(95 \% \mathrm{Cl}, 1.19-2.48)$ the risk of obesity as compared to school children who do not visit restaurant per week. School children taking junk food regularly was also a reason for the risk of obesity. School children consuming junk food had a high prevalence of obesity as compared to school children who do not consume junk food regularly respectively (230/420; 54\% v 45/95; 47\%, $p$-value $=0.005$.) School children had 2.5 times more, $(95 \% \mathrm{Cl}, 1.21$ - 2.9) the risk of obesity of as compared to school children who do not consume junk food regularly.
School children with family history of diabetes had a high prevalence of obesity as compared to school children who do not have family history of diabetes respectively (220/420; 52\% v 29/80; 36\%, $p$-value $=0.02$.) School children with family history of diabetes had 1.15 times more, $(95 \% \mathrm{Cl}, 1.14$ $1.25)$ the risk of obesity as compared to school children who do not have family history of diabetes. School children with family history of obesity had a high prevalence of obesity as compared to school children who do not have family history of obesity respectively (218/420; 51\% v 128/187; 68\%, p-value $=0.01$. School children with family history of obesity had 2.05 times more, $(95 \% \mathrm{Cl}, 1.19-3.28)$ the risk of obesity as compared to school children who do not have family history of obesity see Table 3. All the subjects were briefed about the nature of the study and an informed consent was taken.

Although the research has reached its aims, there was a limitation that needs to be mentioned. Due to time limit this research was conducted only on a small size of population.

The study protocol was approved by ethical review committee. Written informed consent was taken from the participants before their enrolment in this study. The participants' involvement in this study was voluntary and no financial incentives were provided to any study participant.

\section{Discussion}

This study enables us to assess the correlation between obesity, overweight, physically less inactivity and bullying. This study was conducted in the age group from 13 to 18 school going children, through this we found that girls were comparatively more obese, overweight than boys, but boys are more involve in bullying. Obese and overweight students are physically less active which in this study was defined as (mean number of times a sport is played per week that is greater than 45 minutes) mean BMI 
in the non obese children were 23.76 while that in obese were $30.38 \%$. Students were bullied once or more in past couple of months, the most common bully behavior in the class was calling mean names, making fun or teasing others in a hurtful way about $28.19 \%$ students suffered from this behavior. Concerning kicking, hitting, pushing, thrusting, locking in the doors, $20.48 \%$ students suffered twice from this event. The most common bully behavior among seniors was taking away money from juniors, 19\% junior students have passed through this incident, majority of the students bully in more than one places and majority of the victims of bully share their experience with their best friends.

Our results about bullies and bullied are discern from the results in some studies that have reported that bullies used to be depressed and have psychological distress. However, these studies have relied on self-reports of being a bully, and it is least likely that bullies as a group give reliable self-reports of about their behavior with others. Instead, we used the well-validated peer nomination method to collect results from classmates about the roles students play. This method provided identification of bullies (and victims) based on the mutual observation of a large group of students who know and observe all students in a class whereas prior studies had the unexpected finding of a fairly uniform psychological and social picture of bullies and victims [27-29].

This study found that inspite of some common characteristics (example school disengagement problems), these groups are discern which has implications for recognizing them and intervening. For example, nevertheless prior studies could be evaluated as indicating an essentiality to focus on depression in addressing the needs of bullies, this method may be fruitful only for the sub group most probably to self-identify, and not for the group who do not accept that they do bullying. Who is reported as a bully or victim may be arbitrate not only by individuals' behavior but also by the biases of the observer. Lerne proposed a theoretical model for under-standing the correlation between physical appearance and social functioning. His model states that physical appearances impact others to behave differentially within an ambient that has high beauty standards [30-31]. Accordingly, being overweight may be a noticeable mark for bullying behaviors. Inarguably, children discerning their overweight and obese classmates as individuals who tease, get teased, fight, and are selfish and mean, which is entirely quite accordant with concepts associated with an overweight body build [32-33]. Because children are eminently dependent on physical appearance in their social inter-actions, they are probably swayed around concepts associated with physical appearance [34].

From this study we can conclude that physical appearance play a major role in the student behavior, it can give rise to different bullying and bullied behaviors, obese and overweight can be rejected by their peers, victimized by the peer aggressions. Obesity and overweight are directly linked to physically inactivity, junk food eating, more visits to restaurants per week, sedentary life style example watching television or playing video games for hours and inversely related to the sleeping hours and breakfast frequency per week.

\section{Conclusion}

Bullying is common especially with obese school children. Students were victimized by hitting, kicking, pushed or locked in doors by their colleagues and their money was taken away by their seniors in students who were sedentary and obese.

\section{Recommendations}

There should be proper awareness of students regarding bullying and it should be reported to their teachers and parents. Teachers should also be 
educated about bullying, how to stop and there should be no favoritism in class. Students should be encouraged to take part in the physical activities the benefits of physical activities should be told and the awareness session of healthy life style should be conducted annually in schools where parents should also be invited.

\section{Future Research prospects}

There should be interventional studies and awareness should be provided to students, teachers and parents about healthy life style and bullying, this can have potential beneficial effects. Conditions like appearance bias should also be studied because they are one of the main reasons of bullying.

\section{Acknowledgements}

Thanks to Dr Musleh Uddin Kalar regarding his statistical write up and to all coauthors regarding their intellectual contribution.

\section{Conflict of Interest}

The authors declare that they have no competing interests.

\section{References}

1. Global Strategy on Diet, Physical Activity and Health. Child overweight \& obesity. Geneva: World Health Organization; 2014 (http://www.who.int/dietphysicalactivity/childhood/en/, accessed 19 January 2014).

2. Wang $Y$, Lobstein $T$. Worldwide trends in childhood overweight and obesity. Int J Pediatr Obes. 2006;1(1):11-25.

3. Strauss CC, Smith K, Frame C, Forehand R. Personal and interpersonal characteristics associated with childhood obesity. J Pediatr Psychol. 1985 Sep;10(3):337-343.
4. Maddox GL, Back KW, Liederman V. Overweight as social deviance and disability. J Health Soc Behav. 1968 Dec;9(4):287-298.

5. Goldfield A, Chrisler JC. Body stereotyping and stigmatization of obese persons by first graders. Percept Mot Skills. 1995 Dec;81(3 Pt):909-910

6. Harper DC, Wacker DP, Seaborg-Cobb LS. Children's social preferences toward peers with visible physical differences. J Pediatr Psychol. 1986;11(3):323-342

7. Baum CG, Forehand R. Social factors associated with adolescent obesity. J Pediatr Psychol. 1984 Sep;9(3):293-302.

8. Pearce MJ, Boergers J, Prinstein MJ. Adolescent obesity, overt and relational peer victimization, and romantic relationships. Obes Res. 2002 May;10(5):386-393.

9. Olweus D. Bullying at School: Knowledge Base and an Effective Intervention Program. Annals of the New York Academy of Sciences. 1996;794:265-276.

10. What are kids saying about violence? Survey: emotional abuse a bigger concern than physical. CNN; 2002 (http://edition.cnn. com/2002/HEALTH/parenting/07/30/ask.the.kids/index.html, accessed 8 March 2014).

11.The Final Report and Findings of the Safe School Initiative: Implications for the Prevention of School Attacks in the United States. Washington, DC: US Department of Education, Office of Elementary and Secondary Education, Safe and Drug-Free Schools Program, and US Secret Service; 2002 (http://ecap.crc.illinois.edu/ pubs/ivpaguide/appendix/finalreport.html, accessed 7 April 2014).

12. Geckova A, van Dijk JP, Stewart R, Groothoff JW, Post D. Influence of social support on health among gender and socioeconomic groups of adolescents. Eur J Public Health. 203 Mar;13(1):44-50

13. Bullying, Bullycide and Childhood Obesity. Florida: Obesity Action Coalition; 2014(http://www.obesityaction.org/ educational-resources/resource-articles-2/childhood-obesityresource-articles/bullying-bullycide-and-childhood-obesity, accessed on 15 May 2014).

14. Prevention of bullying-related morbidity and mortality: a call for public health policies. Bulletin of the World Health Organization. Geneva: World Health Organization; 2014(http://www.who.int/ bulletin/volumes/88/6/10-077123/en/, accessed 5 June 2014).

15. Strauss CC, Smith K, Frame C, Forehand R. Personal and interpersonal characteristics associated with childhood obesity. J Pediatr Psychol. 1985 Sep;10(3):337-343.

16. Maddox GL, Back KW, Liederman WR. Overweight as social deviance and disability. J Health Soc Behav. 1968 Dec;9(4):287298.

17. Goldfield A, Chrisler JC. Body stereotyping and stigmatization of obese persons by first graders. Percept Mot Skills. 1995 Dec;81(3 Pt 1):909-910.

18. Harper DC, Wacker DP, Cobb LS. Children's social preferences toward peers with visible physical differences. J Pediatr Psychol. 1986 Sep;11(3):323-342. 
19. Baum CG, Forehand R. Social factors associated with adolescent obesity. J Pediatr Psychol. 1984 Sep;9(3):293-302.

20. Pearce MJ, Boergers J, Prinstein MJ. Adolescent obesity, overt and relational peer victimization, and romantic relationships. Obes Res. 2002 May;10(5):386-93.

21. McGuire WJ, McGuire CV, Child P, Fujioka T. Salience of ethnicity in the spontaneous self-concept as a function of one's ethnic distinctiveness in the social environment. J Pers Soc Psychol. 1978 May;36(5):511-20.

22. Janseen I, Criag WM, Boyce WF, Pickett W. Associations between overweight and obesity with bullying behaviors in school-aged children. Pediatrics 2004 May;113(5):1187-94.

23. Mona E. Solberg, Dan Olweus. Prevalence estimation of school bullying with the Olweus Bully/Victim Questionnaire. Aggressive Behavior 203 June;29(3):239-268.

24. Olweus D. Aggression and peer acceptance in adolescent boys: two short-term longitudinal studies of ratings. Child Dev 1977 Dec;48(4):1301-13.

25. Olweus, D. Bullying at school: Basic facts and effects of a school based intervention program. J Child Psychol Psychiatry. 1994 Oct;35(7):1171-1190

26. Children's BMI Tool for Schools. Centers for Diseases Control and Prevention. Atlanta; 2014(http://www.cdc.gov/healthyweight/ assessing/bmi/childrens_BMl/tool_for_schools.html, accessed 10 June 2014).

27.Forero R, McLellan L, Rissel C, Bauman A. Bullying behavior and psychosocial

28. health among school students in New South Wales, Australia: cross sectional survey. BMJ. 1999 Aug;319(7206):344-348

29. Kaltiala-Heino R, Rimpela M, Rantanen P, Rimpela A. Bullying at school--an indicator

30. of adolescents at risk for mental disorders. J Adolesc. 2000 Dec;23(6):661-674

31. Kumpulainen K, Rasanen E. Children involved in bullying at elementary school age: their psychiatric symptoms and deviance in adolescence. An epidemiological sample. Child Abuse Negl. 2000 Dec;24(12):1567-157.

32. Hymel S, Wagner E, Butler LJ. Reputational bias: view from the peer group. In: Asher SR, Coie JD, eds. Peer Rejection in Childhood. New York, NY: Cambridge University Press; 1990.

33. Lerner RM. Nature, nurture, and dynamic interactionism. Hum Dev. 1978;21:1-20.
34. Janssen I, Criag WM, Boyce WF, Pickett W. Associations between overweight and obesity with bullying behaviors in school-aged children. 2004 May;113(5):1187-94.

35. Richard S Strauss. Childhood obesity and self-esteem. Pediatrics. 2000 Jan;105(1):e15.

36. Sekine M, Yamaqami T, Handa K, Saito T, Nanri S, Kawaminami $K$ et al. A dose response relationship between short sleeping hours and childhood obesity: results of the Toyama Birth Cohort study. Child Care Health Dev. 2002 Mar;28(2):163-70.

\section{Comment on this article:}

\section{(A) in $8+\mathbf{S} P$}

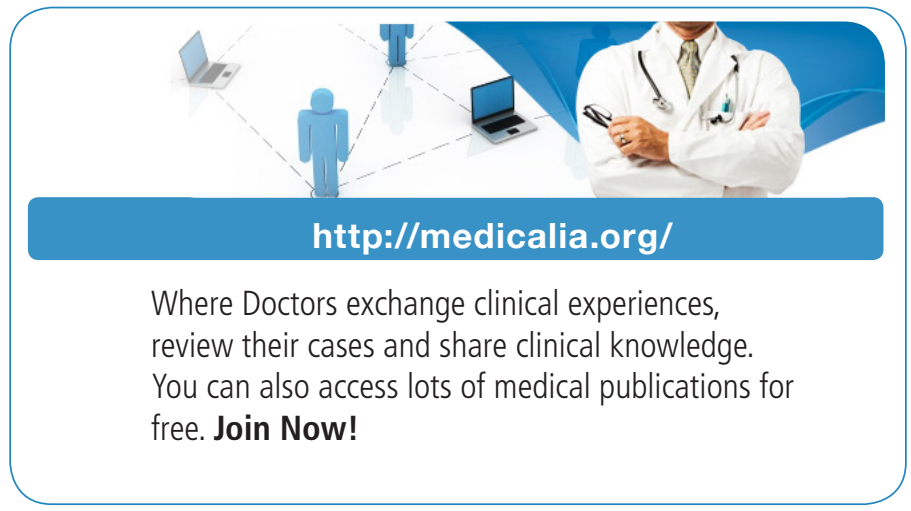

Publish with iMedPub

\section{http://www.imed.pub}

International Archives of Medicine is an open access journal publishing articles encompassing all aspects of medical science and clinical practice. IAM is considered a megajournal with independent sections on all areas of medicine. IAM is a really international journal with authors and board members from all around the world. The journal is widely indexed and classified Q1 in category Medicine. 